\title{
Narrativas no estudo das práticas em saúde mental: contribuições das perspectivas de Paul Ricoeur, Walter Benjamim e da antropologia médica
}

\author{
Narratives in the study of mental health care practices: \\ contributions of the perspectives of Paul Ricoeur, \\ Walter Benjamin and of medical anthropology
}

Rosana Teresa Onocko-Campos ${ }^{1}$
Analice de Lima Palombini ${ }^{2}$
Erotildes Leal $^{3}$
Octavio Domont de Serpa Junior $^{3}$
Ivana Oliveira Preto Baccari $^{1}$
Ana Luiza Ferrer
${ }^{1}$
Alberto Giovanello Diaz
${ }^{1}$
Maria Angélica Zamora Xavier ${ }^{2}$
${ }^{1}$ Departamento de Saúde Coletiva, Faculdade de Ciências Médicas, Universidade Estadual de Campinas. R. Tessália Vieira de Camargo 126, Unicamp. 13.083-887

Campinas SP.

rosanaoc@mpc.com.br

${ }^{2}$ Instituto de Psicologia, Universidade Federal do Rio Grande do Sul. ${ }^{3}$ Programa de Psiquiatria, Instituto de Psiquiatria, Universidade Federal do Rio de Janeiro.

\begin{abstract}
Narratives are ever more frequent in qualitative studies seeking to interpret experiences and the different viewpoints of individuals in a given context. Starting from this concept, the tradition that addresses narrative is reexamined, including the philosophy of Paul Ricoeur, the historical perspective of Walter Benjamin and the field of medical anthropology grounded in phenomenology. In Ricoeur, with hermeneutics as a variation derived from phenomenology, narrative is linked to temporality. In Benjamin, narrative comprised of bits and pieces, always inconclusive, emerges in spite of the official stories. If Ricoeur retrieves tradition from Gadamer as a fundamental component for the construction of the world of a text that makes imitation of life possible, Benjamin, faced with the collapse of tradition, suggests the invention of narrative forms outside the traditional canons, making it possible to hark to the past in order to change the present. Assumptions of medical anthropology are also presented, as they consider narrative a dimension of life and not its abstraction, namely an embodied and situated narrative. Lastly, three distinct research projects in mental health that use narrative linked to the theoretical concepts cited with their differences and similarities are presented.
\end{abstract}

Key words Mental health, Methods, Qualitative research, Narration, Public health
Resumo Narrativas são cada vez mais frequentes em estudos qualitativos para compreender experiências e diferentes visões de sujeitos num dado contexto. Partindo desta concepção, faz-se o resgate de tradições que abordam a narratividadea filosofia de Paul Ricoeur, a perspectiva histórica em Walter Benjamin e o campo da antropologia médica constituída a partir da fenomenologia. Em Ricoeur, tendo a hermenêutica como pensamento derivado e variante da fenomenologia, a narrativaéligada à temporalidade. Em Benjamin, a narrativa, sempre inconclusa, feita de restos e fragmentos, emerge à revelia das histórias oficiais. Se Ricoeur retoma de Gadamer a tradição como componente fundamental para a construção de um mundo do texto com que se torna possivel a imitação da vida, Benjamin, diante da derrocada da tradição, aponta para a invenção de formas narrativas fora dos cânones tradicionais, possibilitando retomar o passado para transformar o presente. Apresentam-se ainda pressupostos da antropologia médica, que considera a narrativa como dimensão do vivido e não sua abstração, ou seja, uma narrativa corporificada e situada. Por fim, apresentam-se três pesquisas distintas em saúde mental que se utilizam de narrativas, articuladas às correntes teóricas apresentadas, com suas diferenças e aproximações.

Palavras-chave Saúde mental, Métodos, Pesquisa qualitativa, Narração, Saúde coletiva 


\section{Introdução}

$\mathrm{O}$ uso de abordagens narrativas em pesquisas de cunho qualitativo no campo da saúde coletiva tem se mostrado cada vez mais frequente em estudos voltados para compreender experiências e diferentes pontos de vista de sujeitos em um dado contexto. Alguns estudos ${ }^{1-6}$ defendem a narrativa como uma ferramenta essencial na construção de significados para a existência humana e demonstram a importância do seu uso como forma de descrever experiências vividas, especialmente em relação ao adoecimento. Também apontam a narrativa como possibilidade de ampliação da prática clínica, discutem diferentes abordagens e estruturas narrativas e enfatizam sua utilização no âmbito de pesquisas qualitativas.

Retomando Burke $e^{7}$ e suas contribuições para a narrativa histórica, trazemos também à tona a importância da estrutura, e não apenas dos acontecimentos, como uma das funções mediadoras da narrativa que interessam ao campo da Saúde Coletiva ${ }^{3}$.

No campo da comunicação, Guimarães ${ }^{8}$ e Leal ${ }^{9}$ tratam a narrativa como espaço de mediação entre indivíduo e sociedade. Somente por meio de um "olhar narrativizante" é que se estabeleceriam nexos entre as experiências no cotidiano e a comunicação, tal como enfatiza Ricoeur ${ }^{10}$, ao destacar que narrativas nada mais são do que "histórias (ainda) não narradas"3.

Lyotard $^{11}$, por sua vez, ao tratar a questão da legitimidade dada àqueles cujas histórias foram narradas, contribui para a percepção de que a variabilidade das vozes e, fundamentalmente, a explicitação de quem são aqueles que falam são parte inseparável do enredo. Ele aponta que é a condição de ouvinte que cria a de narrador. Podemos contar histórias, pois já estamos inseridos na cultura por meio das histórias que nos constituíram como humanos ${ }^{3}$.

Onocko Campos e Furtado ${ }^{3}$ também resgatam Arendt, na leitura que dela faz Julia Kriste$\mathrm{va}^{12}$, para apresentar uma concepção de narrativa atrelada à práxis. A ação empreendida pela narratividade seria característica essencialmente humana, na qual importa, sobretudo, determinar um quem histórico, valorizando o papel do testemunho na construção da história ${ }^{3}$.

No âmbito das pesquisas qualitativas, os objetos de estudo se caracterizam como complexos, na medida em que remetem a problematizações sobre a atividade humana, considerando seus diferentes contextos e momentos históricos. Não há, desse ponto de vista, uma técnica narrativa apro- priada, a qual, quando aplicada, conseguiria responder às perguntas levantadas ou "extrair" a narrativa certa. Isso posto, remete-nos às questões de método em pesquisas qualitativas no campo da saúde coletiva, algo que já vem sendo tematizado, apontando para a necessidade do uso de abordagens que permitam situar os problemas metodológicos no contexto da contemporaneidade ${ }^{13,14}$.

A compreensão do método como um caminho para a certeza absoluta, herdada dos tempos de Descartes, ainda é uma visão hegemônica para a ciência. Esta perspectiva, entretanto, reduz a possibilidade de avanço do pensamento à metodologia da ciência natural, na medida em que a razão - separada da perspectiva histórica e cultural - é considerada a única ferramenta possível para se alcançar a verdade, ou seja, o conhecimento só é possível na esfera da consciência e a partir da neutralidade objetiva do pesquisador.

Contrapondo-se ao pensamento da racionalidade científica, Gadamer ${ }^{15}$ elabora sua obra demonstrando a impossibilidade de um questionamento racional e puro da tradição, uma vez que não é possível nos distanciarmos de nossas referências culturais e históricas. Para este autor, a ideia cartesiana da suficiência do método - entendido como o uso disciplinado da razão - para proteger-nos de qualquer erro torna-se infundada, pois nos encontramos sempre imersos em tradições, e essa imersão não é um comportamento "objetivador", mas um reconhecer-se, já que as tradições afetam-nos e, em grande parte, determinam nossas instituições e atitudes. Assim, podemos dizer que a ideia de uma racionalidade, longe de ser algo fora da tradição, é algo que é transmitido pela tradição.

Por mais cuidadosa que seja a escolha do método usado para investigar o mundo, o pesquisador sempre é parte daquilo que está investigando, pois o mundo é visto a partir de determinada estrutura e dimensão humana. Este é um aspecto que a ciência tende a esquecer. O conceito de história efeitual, desenvolvido por Gadamer ${ }^{15}$, é importante para nos situarmos como investigadores nos nossos desenhos de pesquisa:

Quando procuramos compreender um fenômeno histórico a partir da distância histórica que determina nossa situação hermenêutica como um todo, encontramo-nos sempre sob os efeitos dessa história efeitual. Ela determina de antemão o que se mostra a nós de questionável e como objeto de investigação, e nós esquecemos logo a metade do que realmente é, mais ainda, esquecemos toda a verdade deste fenômeno, a cada vez que tomamos o fenômeno imediato como toda a verdade. 
Para Gadamer ${ }^{15}$, a compreensão tem seu próprio horizonte de significados ou, em outras palavras, tem uma perspectiva sobre o mundo. Este horizonte estará sempre conectado com o passado, não de maneira a nos mantermos presos a ele, mas situados constantemente num presente por meio do qual o passado nos fala. A tradição em si caracteriza-se por ser feita do passado, presente e futuro.

Como bem afirma Lawn ${ }^{16}$ sobre a teoria de Gadamer:

Nossas tentativas de autoentendimento têm um elemento futurista (estamos sempre projetando no futuro desconhecido), mas nossos entendimentos no presente estão sempre relacionando e se fundindo com o passado. A linguagem através da qual articulamos o presente ressoa com os significados do passado e continua sendo operativa no presente; isso dá sentido ao que Gadamer se refere como 'consciência histórica efetiva'.

Filiando-nos a esta postura hermenêutica, pretendemos situar e discutir a construção de narrativas em pesquisas na área da saúde mental, valendo-nos de tradições que abordaram a narratividade - a filosofia de Paul Ricoeur, a perspectiva trapeira da história em Walter Benjamin e o campo da antropologia médica que se constitui tendo por referência a fenomenologia.

\section{Objetivos}

Apresentar três pesquisas distintas em saúde mental que se utilizam de narrativas - pesquisa avaliativa; pesquisa sobre a experiência de adoecimento; pesquisa sobre a experiência de trabalho em saúde mental - e discutir os fundamentos teórico metodológicos das diferentes abordagens narrativas que nelas são utilizadas.

\section{Abordagens narrativas: tradições em diálogo}

\section{Paul Ricoeur: o tempo torna-se humano pela abordagem narrativa}

A narratividade, em Ricoeur, está atrelada à noção de temporalidade. Ao longo de Tempo e Narrativa, Ricoeur ${ }^{10}$ busca fundamentar a inseparabilidade dos dois conceitos na narrativa histórica, na ficcional e na filosófica. Ele assenta tal temática em contraposição à perplexidade com que Santo Agostinho constrói suas aporias diante da percepção da paradoxal existência do tempo, o qual, no mesmo instante em que é, já foi e não é ainda, uma vez que o presente nos escapa e o passado e o futuro não existiriam senão na continuidade daquele que observa o tempo passar ${ }^{10}$.

Para efetivar este diálogo, Ricoeur ${ }^{10}$ retoma a ideia de muthus e de mimesis - respectivamente a tessitura da intriga e a imitação da vida - da Poética de Aristóteles, superando a noção de aporia em prol da de dialética do tempo, cuja temporalidade não mais é questionada, mas aprofunda-se em níveis por meio da estrutura narrativa ${ }^{10}$.

Dentre as diversas maneiras de entender conceitualmente a narratividade, Ricoeur ${ }^{17}$ destaca seu caráter de reciprocidade: tudo o que se pode narrar desenvolve-se em relação ao tempo; e tudo o que transcorre no tempo é passível de ser narrado. Tal qualidade temporal das experiências humanas é a característica que aproxima a ficção da história. Conforme o autor, a trama deve estar articulada para que seja possível reconfigurar com profundidade a experiência temporal humana ${ }^{10}$.

Personagens, sequência temporal, intriga ou enredo, espaço ou circunstância: os componentes fundamentais do gênero narrativo tornamse menos ou mais valorizados de acordo com cada um dos autores abordados. Na obra de Ricoeur, o elemento fundador da estrutura narrativa, o que a define, é o tempo. Tempo e narrativa. O tempo só se verifica pelos elementos narrativos que o recuperam, e a narrativa só pode existir porque o tempo passa.

Para construir uma narrativa, é necessária uma trama de fatos que se disponham de forma inteligível, o que se aproxima da verossimilhança. Ricoeur ${ }^{17}$ assinala que o que caracteriza um começo não é a ausência de acontecimentos anteriores, mas a mera desnecessidade de descrevêlos para que o que venha depois se torne compreensível e sem conteúdos pendentes ${ }^{17}$.

Tratando das tipologias narrativas, Ricoeur $^{17}$ considera a metáfora uma figura de linguagem, para além de sua classificação literária como figura de palavra. Toda criação narrativa é um "criar com regras", ou seja, a elaboração de um processo singular sobre algo já sedimentado, o que significa aceitar que nada é completamente original. Para o autor, além da modificação do sentido atribuído a determinado termo, a novidade da metáfora está em sua relação inovadora com respeito aos demais elementos da frase - tratase, portanto, de uma predicação inesperada. Por meio da metáfora, torna-se factível uma nova pertinência semântica ${ }^{17}$.

É tratando da metáfora que Ricoeur ${ }^{17}$ suspende a dicotomia entre compreender e explicar para pôr em seu lugar uma junção compreender-explicar. Se compreender é encontrar um sen- 
tido no discurso, então a explicação será sempre secundária à compreensão, mas também dela dependente $^{17}$. O texto pode provocar a abertura intencional de seu mundo, o mundo do texto. Afirma Ricoeur ${ }^{17}$ que o mundo do texto intervém no mundo da ação para configurá-lo ou para transfigurá-lo.

Se a função poética da linguagem volta sua ênfase à mensagem em si, a função referencial enfatiza a questão descritiva, configurando para a linguagem dois tipos de movimentos, respectivamente, centrípeto e centrífugo. Por meio de composições intermediárias a esses movimentos, torna-se possível a transfiguração do real. Trata-se, sobretudo, de uma função hermenêutica.

Ricoeur ${ }^{17}$ organiza a definição de hermenêutica em torno de três critérios: 1 . Trata-se de uma filosofia reflexiva. 2. Está na esfera de influência da fenomenologia. 3. Pretende-se uma variante hermenêutica da fenomenologia ${ }^{17}$.

Para Ricoeur ${ }^{17}$, a hermenêutica é reflexiva porque nasce do cogito cartesiano, sofre influência de Kant e da filosofia francesa pós-kantiana já que o pensamento pode acompanhar todas as operações, e a consciência de si é indubitável e almejada (tanto pela fenomenologia quanto para a hermenêutica). Reflexiva, porque por ela buscamos a compreensão de nós mesmos como sujeitos de nossas operações cognitivas, volitivas, estimativas, com clareza intelectual e responsabilidade moral ${ }^{17}$.

Quando Husserl concebe a fenomenologia, atribui-lhe não somente características metodológicas, mas fundamentalmente dá contornos a uma maneira descritiva de articulações fundamentais da experiência, que se firmam em um estado de completa clareza intelectual: por meio do processo de redução, a pergunta fica excluída ao se pôr entre parênteses ${ }^{17}$. Ricoeur ${ }^{17}$ lembra, entretanto, que, se para Descartes toda tentativa de transcendência é duvidosa ao mesmo tempo em que a imanência do eu é indubitável, então a fenomenologia será necessariamente reflexiva. Ora, nesse sentido, conhecer o noema - conteúdo relativo ao ato de conhecimento - sem intermédio da noese - ato de conhecimento - torna-se tarefa impraticável. O movimento infinito de sínteses ativas de que nos fala a fenomenologia dependerá ainda de um quantum infinito de sínteses passivas: a fenomenologia carece da hermenêutica, da mesma forma que a hermenêutica depende da fenomenologia, por ser dela descendente. Há algo que sempre será pressuposto e que se constitui em paraíso perdido da fenomenologia e em possibilidade resgatada da hermenêutica. Por outro lado, a hermenêutica estará fadada à influência reflexiva de sua gênese fenomenológica ${ }^{17}$.

Ainda que o ressurgimento da hermenêutica no século XIX esteja relacionado ao entrelaçamento das técnicas de interpretação da exegese bíblica, da filosofia clássica e da jurisprudência, portanto, não diretamente relacionada às questões da fenomenologia, Ricoeur ${ }^{17}$ constrói o percurso compreensível que nos permite considerar a hermenêutica reflexiva e a da esfera fenomenológica. Desde Heidegger, torna-se condição da filosofia o estabelecimento de um vínculo ontológico mais primitivo a que se subordina a relação sujeitoobjeto. A redução deixa de ser um gesto primário para compor-se em significado epistemológico secundário, já que estamos previamente no mundo para poder julgá-lo e submetê-lo a determinado domínio. Assim, a hermenêutica pós-heideggeriana se faz herdeira da fenomenologia e é, a um só tempo, sua inversão e sua realização: a hermenêutica se emancipa do idealismo que Husserl tentou atribuir à fenomenologia ${ }^{17}$.

Para Ricoeur ${ }^{17}$, o problema de submeter um texto à compreensão não se distingue do problema da compreensão de qualquer outro objeto, mas constitui-se em uma particularidade. Somase a essa particularidade aquilo que o autor denomina tríplice autonomia do texto: em relação à intenção do autor, à recepção do leitor e ao contexto histórico, social, econômico e cultural de sua produção ${ }^{17}$. Com isso, a tarefa da hermenêutica será doravante perscrutar a obra e a capacidade desta de dar lugar a um mundo. Estabelece-se assim uma dinâmica a um só tempo interna e externa, que pressupõe a junção de compreensão e explicação.

Defendendo uma necessária dialética entre compreender e explicar, Ricoeur ${ }^{17}$ opõe-se às ilusões tanto da compreensão intersubjetiva imediata quanto de que a análise estrutural dos signos isoladamente possa encerrar-lhes em alguma objetividade. Assinala que o texto tem sempre a pretensão de fazer emergir um mundo, quer seja uma experiência ou uma forma de viver e nele estar - algo já existente e que pede passagem à linguagem, aproximando-se das concepções de Heidegger e de Gadamer ${ }^{17}$.

\section{Narrar a história a contrapelo com Walter Benjamin}

Para Walter Benjamin, a narração tem como alvo a transformação do presente. A relação entre história e tempo ganha aqui outro estatuto: nem a linearidade temporal do historicismo nem a espiral do tempo no círculo hermenêutico; em 
Benjamin, o tempo se conta aos saltos. Aquilo que rompe a linha contínua com que se narra a História oficial diz de um "tempo de agora" (Jetzseit), não cronológico, mas intensivo, remetendo tanto à noção de origem (Ursprung) como surgimento do passado no presente quanto a um evento do instante, que advém a si sem partir de lugar nenhum. A contrapelo, portanto, das histórias oficiais, nas suas brechas, nas suas ruínas, nas histórias não contadas dos vencidos (barbárie) que subjazem aos seus monumentos (cultura) - é onde Benjamin situa, ética e politicamente, o ofício do historiador. Interessado nos restos, nos trapos do passado que foram esquecidos e que jazem inúteis, arrancando-os do contexto em que foram encerrados para arranjá-los em novos ordenamentos, consoantes ao presente, o historiador benjaminiano age como um trapeiro e colecionador. A narração da história, assim, não trata de enumerar sequencialmente os acontecimentos, mas, "fazendo emergir momentos privilegiados para fora do continuum cronológico" ${ }^{18}$, permite a apreensão desses momentos estelares numa constelação inédita e salvadora. Ou seja, o passado, se pode ser retomado, é na sua precariedade, como perda e esquecimento, numa não identidade consigo mesmo - abertura sobre o futuro, inacabamento constitutivo ${ }^{18}$.

Esta leitura, que se depreende ao longo da obra de Benjamin e se reafirma em seu último texto, em 1940, Sobre o conceito de História ${ }^{18-20}$, distancia-se da que busca identificar em Benjamin o conservador nostálgico da tradição. Com efeito, a perda da tradição e a impossibilidade da narração em seus cânones tradicionais, temas que lhe são recorrentes, comparecem quase simultaneamente, e sob perspectivas divergentes, em dois ensaios do autor escritos no ano de 1936. Experiência e Pobreza, o primeiro deles, situa a experiência (Erfahrung) no contexto de uma tradição compartilhada, transmitida por um pai agonizante a seus filhos, visando uma prática comum, válida para toda a coletividade ${ }^{21}$. Já $O$ narrador identifica o ato de narrar à capacidade de intercambiar experiências, capacidade manifesta nas figuras arquetípicas do narrador - o camponês sedentário, o marinheiro viajante e o artífice das cidades medievais que se estabelece após migrar de oficina em oficina como aprendiz ${ }^{22}$. Essa temporalidade e essa espacialidade próprias às sociedades artesanais, que tornam possível o fio continuum de suas narrações, são substituídas pelo "tempo deslocado e entrecortado do trabalho no capitalismo moderno"18, tempo submetido à imediatez da informação midiática que, no mesmo instante em que dissolve as distâncias espaciais, torna-nos incólumes às catástrofes do mundo. É a ocasião, diz Benjamin, para o florescimento do Romance como gênero literário, consagrado à solidão - do autor, do herói, do leitor ${ }^{18}$-, onde o que conta não é mais a experiência compartilhável (Erfahrung), mas o vivido (Erlebnis) nessa esfera de intimidade. No entanto, Benjamin aponta para a possibilidade de invenção de outras formas narrativas, distintas da informação e do romance, a partir da derrocada do mundo narrativo da tradição. Se esta possibilidade é positivamente afirmada em Experiência e pobreza, na alusão a uma miríade de formas narrativas que acolhem com o ímpeto da irreverência esses novos tempos, no texto $O$ narrador, de tom mais contido, Benjamin não oferece mais do que algumas pistas na direção de uma atividade narrativa capaz de rememorar o passado fora dos cânones da tradição ${ }^{18}$.

Acompanhemos Gagnebin no encalço dessas pistas, a partir de um parágrafo de Benjamin que se repete em ambos os ensaios, no qual ele chama atenção para o silêncio com que haviam retornado do campo de batalha os combatentes da Primeira Guerra: o seu sofrimento não era comunicável, voltavam pobres, e não ricos, de experiências $^{21,22}$. Nas palavras de Gagnebin ${ }^{18}$ :

O que se opõe a essa tarefa de retomada salvadora do passado não é somente o fim de uma tradição e de uma experiência compartilhadas; mais profundamente, é a realidade do sofrimento, de um sofrimento tal que não pode depositar-se em experiências comunicáveis [...] Como descrever esta atividade narradora que salvaria o passado, mas saberia resistir à tentação de preencher suas faltas e de sufocar seus silêncios? [...] que saberia [deixar o passado] inacabado, assim como, igualmente, saberia respeitar a imprevisibilidade do presente?

Narrar a impossibilidade de narrar, eis uma das pistas, de que a obra de Kafka se mostra pródiga aos olhos de Benjamin: Kafka, grande narrador, capaz de compartilhar com outros, não conselhos, mas sua própria desorientação, não estando dados nem o retorno a um mundo ancestral nem a invenção apressada e salvadora de um novo mundo. As qualidades que o narrador tradicional tirava da rica tradição na qual se enraizava, Kafka, por sua parte, as conquistou a duras penas no terreno solapado de uma tradição morta e de uma identidade em migalhas ${ }^{18}$. A queda da tradição se revela, assim, o lugar de possibilidade - ainda que não garantida - de uma retomada inventiva e imperiosa da narração. Nela, o esquecimento se faz também condição da memória, marca da sua finitude. 
Benjamin é, ele também, um narrador dessa espécie, um trapeiro colecionador de ruínas, de que sua obra - em sua descontinuidade e inacabamento - dá-nos testemunho. A esse respeito, e considerando a estreita relação entre o pensamento que Benjamin professa e o método com que conduz a montagem de seus escritos e o andar de sua vida (na quase indistinção entre obra e vida), reportamo-nos ainda a Gagnebin ${ }^{18}$ para um último apontamento acerca do uso muito particular da narrativa em primeira pessoa no texto Infância berlinense ${ }^{23}$. Este texto, em que Benjamin se serve do fio das lembranças de infância tecido na urdidura do esquecimento, pode ser lido como uma homenagem a Proust em sua busca infinita por um tempo perdido, na justa medida em que esse infinito rompe a noção corriqueira de autobiografia - pois o autos não é mais o mesmo, o bios explode em várias vidas que se entrecruzam e a grafia segue o entrelaçamento de diversos tempos que não são ordenados por uma linearidade exclusiva ${ }^{18}$. Contudo, Infância Berlinense nos dá também a medida da distância que Benjamin, de forma deliberada, toma do texto proustiano pelas condições individualistas de sua produção, condições que lançam seu autor no risco de uma espécie de devaneio complacente e infinito do qual o sujeito não mais quer emergir ${ }^{18}$. No trabalho das Passagens, Benjamin ${ }^{24}$ impunhase já a exigência política e ética de confrontar o sonho com a vigília e, deste confronto, no momento do despertar, extrair os elementos que lhe permitissem agir - um agir coletivo levando à transformação do presente. Assim, além da intensidade das lembranças individuais, Infância berlinense reconstrói a densidade de uma memória pessoal e coletiva, aberta à dimensão inconsciente do sujeito, mas também à sua dimensão social, que recusa a particularidade individual e é atravessada "pelas ondas de desejos, de revoltas, de desesperos coletivos"18. O "eu" que fala da criança, na lembrança do adulto, diz de uma subjetividade que não se reduz às particularidades do menino Benjamin. Sua voz nos atinge profundamente - mas teríamos a maior dificuldade em descrever a identidade específica deste meni$n o^{18}$. Gagnebin reporta-se aqui à distinção estabelecida por Paul Ricoeur entre uma identidademesmidade, referida ao eu zeloso de si da autobiografia clássica, e as figuras da sua ipseidade, que dão lugar a um sujeito que, ao enunciar "eu”, deixa-se "atravessar pelos diversos tempos da sua história - e da história [prescindindo] das definições sempre ilusórias de si mesmo"18.

\section{Narrativas sobre experiência \\ de adoecimento na perspectiva \\ da antropologia médica \\ de base fenomenológica}

A narrativa é, sem dúvida, um dos pilares do campo de estudos da antropologia e saúde. O modo de concebê-la, entretanto, não é único. Hydén, em Illness and Narrative ${ }^{25}$, artigo de revisão sobre dez anos de estudos sobre narrativa de adoecimento (illness narrative), indicou o quanto eram plurais as formas de abordar e conceber as narrativas nos estudos sobre a experiência de adoecimento (illness experience). Essa diversidade pôde ser percebida também no número especial da Social Science \& Medicine - Narrative Representations of Illness and Healing ${ }^{26}$ - publicado na mesma década.

De forma breve e esquemática, podem-se indicar pelo menos dois grandes modos de conceber as narrativas neste campo. Um deles enfatiza os aspectos simbólicos e culturais que as determinam. Nesta perspectiva interessam os sistemas ordenados de ideias, símbolos e representações que lhes atribuem sentido e significam o adoecimento (illness) e os processos de tratamento e cura. As experiências e as práticas cotidianas dos sujeitos doentes e de seus terapeutas não são aí consideradas. O outro modo de tratar as narrativas considera-as como uma dimensão do vivido e não exclusivamente como uma representação ou abstração acerca deste. Ou seja, nesta segunda tradição, a narrativa é também um território existencial e experiencial, onde os sujeitos adoecidos conjugam individualmente as normas, os valores e as expectativas sociais, culturais e coletivas e desenvolvem formas específicas de pensar, explicar e agir nas situações vividas cotidianamente que dizem respeito ao seu adoecimento. Para fins deste artigo, apresentaremos os pressupostos que sustentam, no campo da antropologia médica, a segunda concepção de narrativa e um pouco de sua historicidade.

A tradição da antropologia médica que concebe a narrativa como "parte da vida, antes de se exilar na escrita", como a descreveu Ricoeur ${ }^{27}$, pode ser considerada fenomenologicamente sensível. Dentre os seus representantes internacionais, citamos Arthur Kleinman ${ }^{28}$, Byron Good ${ }^{28}$, Lawrence Kirmayer ${ }^{29}$, Ellen Corin ${ }^{30}$ e Thomas Csordas $^{31}$. No Brasil, o destaque fica para Miriam Cristina M. Rabelo e Paulo Cesar B. Alves ${ }^{32}$. Para esta abordagem, conhecer como as pessoas vivem o seu mundo é central. $O$ interesse que dirige 
esta tradição é saber como os indivíduos compreendem e atuam nas situações de adoecimento que experimentam ao longo da vida. Visto que este conhecimento não pode ser integralmente deduzido das representações abstratas ou das concepções sociais que o adoecimento carrega em cada cultura, expressas através das narrativas, impõe-se que a experiência vivida, em especial a de adoecimento, ganhe centralidade. Este privilégio dado à experiência se constitui em um dos elementos que demandará a revisão da concepção de narrativa como abstração, simples relato de experiência ou mesmo invenção da cultura.

A experiência vivida é o que desvela o modo de estar no mundo dos indivíduos. Como o vivido é sempre encarnado corporalmente e em contexto, quando esta tradição atribui visibilidade à experiência vivida, corpo e intersubjetividade são iluminados. Constitui-se assim o tripé que suportará a ideia de narrativa corporificada e situada.

Como sugerem Good et al. ${ }^{33}$, o corpo é o que nos situa no espaço e "meio" através do qual cotidianamente manipulamos e significamos os objetos que constituem o mundo onde estamos imersos. Habitar o próprio corpo é conviver com seu duplo aspecto de corpo vivido e corpo objetivo, que oferece a condição primeira da intersubjetividade como intercorporeidade ${ }^{31}$. Pensar o serem-situação implica "considerar a unidade corpo-mente e também o enraizamento do indivíduo no contexto social, enquanto ser que é desde sempre ser-com-outros"32.

Locus onde as várias dimensões da vida simultaneamente emergem e se inscrevem, o corpo é base de todo e qualquer conhecimento e ação que possamos realizar no mundo, encarnando, de forma particular e única, o conhecimento e a experiência acumulados acerca desta ação e das possibilidades de novas intervenções na realidade. Deste modo, o corpo protagoniza uma relação não reflexiva com o mundo, perceptível pela forma como se adequa a cada situação vivida. A narrativa se apresenta, assim, como a possibilidade de expressão dessa experiência corpo-mundo.

Produto do corpo em situação - corpo que atualiza uma relação com o mundo que não é mediada, a priori, pela apreensão intelectual, mas a precede -, a narrativa adquire, no campo da antropologia de inspiração fenomenológica, uma dimensão corporificada. Esta dimensão lhe atribui uma qualidade antes não percebida ${ }^{34}$. O reconhecimento de uma diferenciação possível entre o conhecimento através do qual se vive a vida e o conhecimento através do qual a explicamos abre a possibilidade de considerar que as narrativas não sejam todas e sempre "explicações" sobre a vida.

Em artigo intitulado Embodied Narratives, Menary $^{34}$ identifica dois tipos de narrativas - as autobiográficas e as intersubjetivas -, ampliando a compreensão acerca desta outra concepção de narrativa. As narrativas que nomeia "autobiográficas" - aquelas em que contamos a nossa vida para outros, para nós mesmos, ou antecipamos o futuro e a direção de desdobramentos de nossa vida - são, segundo ele, as de mais forte caráter reflexivo. A função intersubjetiva destas narrativas é dizer nossa história de vida a outros, mas a sua principal função é ampliar a nossa compreensão de nós mesmos, com e no mundo. Embora Menary ${ }^{34}$ não indique isso de modo explícito, um alto potencial explicativo parece estar associado ao caráter reflexivo de tais narrativas.

O segundo tipo de narrativa - intersubjetiva - é aquela com menos potência para "explicar” a vida. Diz muito mais sobre o campo das ações que sobre o campo da reflexão, como descrito acima. Neste segundo tipo de narrativa, o narrado é sobretudo a experiência corporificada de um sujeito no mundo e menos uma tematização sobre esta vivida. Este segundo tipo de narrativa indica a dimensão corporificada de toda e qualquer narrativa - dimensão pouco visível quando apenas as narrativas que explicam as nossas experiências são levadas em conta.

O debate sobre a dimensão corporificada das narrativas - protagonizado por filósofos, estudiosos da cognição e antropólogos - não teve, entretanto, consequências imediatas e diretas para a concepção de narrativa nesta tradição da antropologia médica. Foram Kirmayer ${ }^{29}$, Alan Young ${ }^{35}$ e Grouleau et al. ${ }^{36}$ os que desencadearam essa revisão. Eles identificaram que a literatura sobre narrativa de experiência de adoecimento estava dominada pela concepção reflexiva, que tem o propósito de explicar a experiência vivida de adoecimento. Estes autores perceberam que a ideia de Kleinman ${ }^{37}$ - de que as narrativas de experiência de adoecimento obedecem a esquemas lógicos e coerentes e se organizam em torno de atribuições causais - havia se tornado hegemônica. A despeito da centralidade da noção de experiência de adoecimento e da sua relação intrínseca com a corporeidade, o foco exclusivo em modos explicativos de narrar ignorou o caráter multifacetado da experiência de adoecimento. A explicação do vivido a partir da perspectiva causal não foi tomada como uma forma, dentre outras, de vivenciar/ narrar os processos de adoecimentos. 
Considerado o fluxo do processo de adoecimento, o modo explicativo de narrar requer, em geral, a elaboração do vivido através da reflexão sobre a experiência de adoecimento. Esse exercício demanda tempo e não costuma se produzir imediatamente quando o sujeito se vê surpreendido pelo adoecimento. Nos momentos iniciais do processo de adoecimento, as narrativas por complexos em cadeia, por contiguidade temporal e espacial, são uma forma possível de narrar a experiência. Partindo do corpo em ação na situação, elas abrem ao sujeito adoecido a possibilidade de atribuição de sentido à experiência vivida. Contar a experiência a partir de exemplos, da suposição de semelhança e diferença do vivido próprio face àquele por outros, foi também junto com a narrativa por complexo em cadeia outra forma de narrar, percebida quando a corporeidade se fez central para a narrativa. Esta, mostrou-se, então, quando liberta do jugo do modelo explicativo, reveladora da dimensão préreflexiva da existência e do conhecimento tácito através do qual se vive. Este conhecimento - tácito - é condição de possibilidade para a elaboração do conhecimento e da narrativa através do qual explicamos a vida, indicando que a experiência vivida não se resume nem se encerra na explicação que podemos ter sobre ela.

\section{Pesquisas em saúde mental} com abordagens narrativas

Três foram as tradições que resgatamos para pensar o uso da narratividade. Três escolhas, todavia, não aleatórias, pois são aquelas que se fizeram passíveis de aplicabilidade para a pesquisa no campo de interface entre a Saúde Mental e a Saúde Coletiva. A seguir, apresentam-se exemplos de seu uso em estudos de grande porte e discutem-se suas possíveis complementaridade e imbricações.

Em pesquisas avaliativas e participativas em serviços públicos de saúde ${ }^{38-40}$, baseadas na hermenêutica gadameriana e na teoria narrativa de Paul Ricoeur, utilizou-se a transcrição das gravações de grupos focais com gestores, trabalhadores, usuários e familiares para a construção de narrativas. Após uma primeira rodada de grupo focal com cada grupo de interesse, foram identificados e extraídos, do material transcrito, núcleos argumentais que respondiam às questões colocadas pelas pesquisas. Estes constituíram o fio condutor para a construção das narrativas, a partir do dito pelos participantes e respeitandoo. Em uma segunda rodada, essas narrativas foram apresentadas aos mesmos participantes dos grupos anteriores, para que pudessem contestálas, corrigi-las e validá-las, a maioria das vezes conseguindo aprofundar o discutido no primeiro grupo ${ }^{3}$. Após a transcrição da segunda roda$\mathrm{da}$, foram construídas novas narrativas que, junto àquelas dos primeiros grupos, constituíramse material-base para a construção de parâmetros e dispositivos avaliativos. Com esta escolha, pretendíamos não somente contar uma história unica e cronologicamente arranjada, mas, sobretudo, compreender os processos de trabalho e as trocas que acontecem no cotidiano [dos serviços $]^{38}$.

Em pesquisa orientada pela concepção de experiência em Benjamin ${ }^{41}$, voltada para trabalhadores de serviços residenciais terapêuticos, investigaram-se os efeitos, sobre as práticas de cuidado e sobre a percepção de si como cuidadores, que o compartilhamento de narrativas referidas às experiências no cotidiano desses serviços podia produzir. Foram narrativas curtas e fragmentárias as que escreveram esses trabalhadores, através das quais se retomaram rasgos do passado que, iluminando o presente, redesenhavam um futuro. A cada encontro proposto pela pesquisa, era trabalhado o texto previamente escrito por um dos participantes, através de leitura coletiva, comentários, sugestões. Esse trabalho visava não apenas a melhor legibilidade das ideias propostas pelo autor do texto, mas o compartilhamento da experiência por ele protagonizada e sua elaboração coletiva. A intervenção proposta pela pesquisa tomava a forma de uma experiência de passagem do eu ao plural. Para além da intensidade das lembranças individuais, as narrativas que foram assim elaboradas iam construindo a densidade de uma memória ao mesmo tempo pessoal e coletiva, levando a transformações do agora.

Em pesquisa sobre a experiência de adoecimento inscrita no campo da antropologia e saúde de orientação fenomenológica, objetivou-se conhecer a perspectiva de psiquiatras e de usuários de serviços de saúde mental sobre a experiência do adoecimento em pessoas diagnosticadas com transtornos do espectro esquizofrêni$\mathrm{CO}^{42}$. Foram feitos vários grupos focais: com usuários, com psiquiatras e com ambos juntos. Os grupos foram audiogravados, transcritos e, posteriormente, categorizados e codificados de modo a contemplar os três grandes momentos no processo de adoecimento: antecedentes, crise/início do adoecimento e restabelecimento/não restabelecimento. Nesta perspectiva, a narrativa, ao fornecer diferentes contornos aos distintos modos de viver a experiência ${ }^{43}$, é mais do que um meio de comunicá-la, ou meramente a forma pela qual 
a experiência é representada, simbolizada e recontada; trata-se de uma dimensão inerente a ela própria $^{42}$. A ênfase, então, é colocada na descrição, sendo necessário que esta explicite o que está implícito na experiência vivida, corporal e préreflexiva, um modo de narrar no qual o adoecimento seja explicitado de modo mais corporificado, menos reflexivo; ou seja, um modo em que os significados atribuídos à experiência apresentam-se mais próximos àquela pré-objetiva da corporeidade ${ }^{44}$.

As narrativas, na pesquisa citada sobre a experiência do adoecimento na esquizofrenia, focam-se na descrição do vivenciado e, portanto, são apresentadas como unidade narrativa, tal como foram expressas pelos participantes da pesquisa, sendo posteriormente categorizadas e codificadas pelos pesquisadores. O objetivo é favorecer que narrativas encarnadas revelem a dimensão pré-reflexiva e experiencial do viver com esquizofrenia. Já na pesquisa informada pela teoria narrativa de Ricoeur, o conhecimento da experiência é subsídio para a análise e a avaliação dos processos de trabalho, em que a construção das narrativas por parte dos pesquisadores - com destaque de núcleos argumentais explicitando experiências, consensos e dissensos - produz efeitos de narratividade ${ }^{14}$ que enriquecem a espiral hermenêutica. Por fim, na pesquisa de inspiração benjaminiana, mais do que o conhecimento da experiência através das narrativas, é o compartilhamento dessas narrativas - inacabadas, entrecortadas, fora de ordem - o que pode conferir caráter de experiência ao vivido, levando à reinvenção do presente.

\section{Considerações Finais}

No âmbito da saúde Coletiva, o estudo das práticas tem se mostrado um campo fértil e instigante. Quando a pesquisa busca se aproximar dos novos serviços (como no caso da saúde mental, que experimentou grande expansão em tempos recentes) ou estudar práticas inovadoras (como as advindas da Reforma Psiquiátrica), o recurso às abordagens narrativas tem sido cada vez mais frequente. Contudo, ainda poucos trabalhos discutem as relações entre abordagem teórica, suas variações metodológicas e as implicações dessas escolhas nas investigações.

Buscamos, no presente artigo, explicitar alguns dos principais pressupostos de três correntes de abordagem narrativa que têm sido utiliza- das na Saúde Coletiva e, com exemplos de sua aplicação concreta, estabelecer as articulações entre essas abordagens e sua utilidade nesta área.

Destacamos a relevância atual da intersecção desses campos de saber como um promissor de investigação, compromissado tanto com as experiências encarnadas e em primeira pessoa (intransferíveis, portanto) - como ocorre quando queremos saber como foi viver determinada forma de adoecer, os percursos dos pacientes e suas percepções -, quanto com a importância e a necessidade de sua 'traducibilidade' para o campo das políticas e das práticas, no sentido de contribuir para formar serviços mais porosos e plásticos às necessidades dos usuários e que incorporem construtivamente as experiências e os aprendizados de seus trabalhadores. Isso nos obriga a considerar a necessária miscigenação-inovaçãocriação que o campo dos estudos das práticas de saúde nos apresenta, incluindo aqui os aspectos éticos e clínicos envolvidos nos desenhos.

Chamamos atenção para o fato de as abordagens etnográficas clássicas assumirem muitas vezes o pressuposto de que uma boa aculturação resolveria a maioria dos problemas técnicos, sobretudo em relação à qualidade do material construído narrativamente, dando pouca ênfase, por exemplo, à intersubjetividade. Esta se destacou sobremaneira nos estudos que referimos, provavelmente por se tratar - direta ou indiretamente - de pesquisas envolvendo diagnosticados dentro do espectro psicótico, que sabidamente nos oferecem histórias fragmentadas, em uma ordenação singular e não submetidas à lógica retórica habitual.

Também propusemo-nos analisar as singularidades/diferenças no modo de fazer pesquisa de práticas em saúde mental: na pesquisa avaliativa, ousamos a construção narrativa como forma de produzir um material denso e que permitisse maior aprofundamento das questões em estudo; na pesquisa sobre a experiência de adoecimento, respeitamos as construções originais dos usuários, pois não desejávamos racionalizar nem dar um ordenamento alheio à experiência encarnada; na pesquisa com trabalhadores, valemonos de narrativas inconclusas e fragmentadas para produzir compartilhamento e reflexão, gerando efeitos de transformação nas equipes.

Sem pretensões de exaurir completamente nenhuma das abordagens apresentadas, mas, antes, propondo-se iniciar uma possível articulação entre elas, o presente estudo almeja contribuir com o debate metodológico na saúde coletiva. 


\section{Colaboradores}

RT Onocko-Campos, AL Palombini, E Leal, OD Serpa Júnior, IOP Baccari, AL Ferrer, AG Diaz e MAZ Xavier participaram igualmente de todas as etapas de elaboração do artigo.

\section{Referências}

1. Vieira AG. Do Conceito de Estrutura Narrativa à sua Crítica. Psicologia: Reflexão e Crítica 2001; 14(3):599-608.

2. Fonte CA. A narrativa no contexto da ciência psicológica sob o aspecto do processo de construção de significados. Psicologia: Teoria e Prática 2006; 8(2):123-131.

3. Onocko Campos RT, Furtado JP. Narrativas: utilização na pesquisa qualitativa em saúde. Rev Saude Publica 2008; 42(6):1090-1096.

4. Nunes ED, Castellanos MEP, Barros NFd. A experiência com a doença: da entrevista à narrativa. Physis 2010; 20(4):1341-1356.

5. Favoreto CAO, Camargo Júnior KRd. A narrativa como ferramenta para o desenvolvimento da prática clínica. Interface (Botucatu) 2011; 15(37):473-483.

6. DasGupta S. Las historias importan: Narrativa, Salud y Justicia Social. Conexión Pediátrica 2012; 5(1):14.

7. Burke P. A escrita da história: novas perspectivas. São Paulo: Editora Unesp; 1992.

8. Guimarães C. O Ordinário e o extraordinário das narrativas. In: Guimarães C, França V, organizadores. Na mídia, na rua: narrativas do cotidiano Belo Horizonte: Autêntica; 2006. p. 7-17.

9. Leal B. Saber das narrativas: narrar. In: Guimarães C, França V, organizadores. Na mídia, na rua: narrativas do cotidiano. Belo Horizonte: Autêntica; 2006. p. 19-27.

10. Ricoeur P. Tempo e narrativa. Tomo I. Campinas: Papirus Editora; 1994.

11. Lyotard JF. A condição pós-moderna. 9a Edição. Rio de Janeiro: José Olympio; 2006.

12. Kristeva J. O gênio feminino: a vida, a loucura, as palavras. Rio de Janeiro: Rocco; 2002. Volume 1.

13. Onocko Campos R. Pesquisa qualitativa em Políticas, Planejamento e Gestão em Saúde Coletiva. In: Barros NF, Cecatti JG, Turato ER, organizadores. Pesquisa Qualitativa em Saúde - múltiplos olhares. Campinas: Ed. Unicamp; 2005. p. 261-271.

14. Campos RO. Fale com eles! O trabalho interpretativo e a produção de consenso na pesquisa qualitativa em saúde: inovações a partir de desenhos participativos. Physis 2011; 21(4):1269-1286.

15. Gadamer H-G. Verdade e Método: traços fundamentais de uma hermenêutica filosófica. Tradução de Flávio Meurer. Petrópolis: Editora Vozes; 1997.

16. Lawn C. Compreender Gadamer. Petrópolis: Vozes; 2006.

17. Ricoeur P. Documentos - Narratividad, fenomenología y hermenéutica. Anàlisi 2000; 25:189-207.

18. Gagnebin JM. História e narração em W. Benjamin. São Paulo: Perspectiva; 2004

19. Benjamin W. Sobre o conceito da História. In: Benjamin W. Obras escolhidas I. Magia e técnica, arte e política. 7a Edição. São Paulo: Brasiliense; 1994. p. 222-234. 
20. Seligmann-Silva M. A atualidade de Walter Benjamin $e$ de Theodor W. Adorno. Rio de Janeiro: civilização Brasileira; 2010.

21. Benjamin W. Experiência e pobreza. In: Benjamin W. Obras escolhidas I. Magia e técnica, arte e politica. 7a Edição. São Paulo: Brasiliense; 1994. p. 114-119.

22. Benjamin W. O narrador. Considerações sobre a obra de Nikolai Leskov. In: Benjamin W. Obras escolhidas I. Magia e técnica, arte e política. 7a Edição. São Paulo: Brasiliense; 1994. p. 197-221.

23. Benjamin W. Infância em Berlim por volta de 1900. In: Benjamin W. Obras escolhidas II. Rua de mão única. 5a Edição. São Paulo: Brasiliense, 1995.

24. Benjamin W. Passagens. Edição alemã de Rolf Tiedemann; organização da edição brasileira Willi Bolle, com a colaboração de Olgária Chain Feres Matos. Belo Horizonte, São Paulo: Editora UFMG Imprensa Oficial do Estado de São Paulo; 2006.

25. Hydén LC. Illness and narrative. Sociology of Health \& Illness 1999; 19(1):48-69.

26. Garro LC, Mattingly C. Narrative Representations of Illness and Healing. Soc Sci Med 1994; 38(6):771774

27. Ricoeur P. Soi-même comme un autre. Paris: Éditions Du Seuil; 1990.

28. Kleinman A, Eisenberg L, Good B. Culture, Illness, and Care Clinical Lessons from Anthropologic and Cross-Cultural Research. Ann Intern Med 1978; 88(2):251-258

29. Kirmayer L. The Body's Insistence on Meaning: Metaphor as Presentation and Representation in Illness Experience. Medical Anrhropology Quarterly 1992; 6(4):323-346.

30. Corin E, Lauzon G. From Symptoms to Phenomena: The Articulation of Experience in Schizophrenia. Journal of Phenomenological Psychology 1994; 25(1):3-50.

31. Csordas TJ. Intersubjectivity and intercorporeality. Subjectivity 2008; 22:110-121.

32. Rabelo MC, Alves PCB. Experiência de doença e narrativa. Rio de Janeiro: Editora Fiocruz; 1999

33. Good BJ, Del Vecchio Good MJ, Togan I, Ilbars Z, Güvener A, Gelisen I. In the subjective mode: Epilepsy narratives in Turkey. Soc Sci Med 1994; 38(6):835-842.

34. Menary R. Embodied Narratives. Journal of Consciousness Studies 2008; 15(6):63-84.

35. Young A. Rational men and the explanatory model approach. Cult Med Psychiatry 1982; 6(1):57-71.

36. Grouleau D, Young A, Kirmayer LJ. The McGill Illness Narrative Interview (MINI): An Interview Schedule to Elicit Meanings and Modes of Reasoning Related to Illness Experience. Transcult Psychiatry 2006; 43(4):697-717.
37. Kleinman A. Patients and healers in the context of culture: An exploration of the borderland between anthropology, medicine, and psychiatry. Berkeley: University of California Press; 1980.

38. Onocko Campos RT, Furtado JP, Miranda L, Ferrer AL, Passos E, Gama CAP. Avaliação da rede de centros de atenção psicossocial: entre a saúde coletiva e a saúde mental. Rev Saude Publica 2009; 43(Supl. 1):16-22.

39. Onocko Campos RT, Gama CA, Ferrer AL, Dantas DV, Stefanello S, Trapé Tl, Pôrto KF. Saúde mental na atenção primária à saúde: estudo avaliativo em uma grande cidade brasileira. Cien Saude Colet 2012; 16(12):4643-4652.

40. Onocko Campos RT, Campos GWS, Ferrer AL, Correa CRS, Madureira P, Gama CA, Dantas DV, Nascimento RS. Avaliação de estratégias inovadoras na organização da Atenção Primária à Saúde em Campinas/SP/Brasil. Revista de Saúde Pública 2012; 46(1):43-50.

41. Palombini AL, Barboza RP, Fick TK, Bkowski G. Cuidando do cuidador: da demanda de escuta a uma escrita de si. Rev. latinoam. psicopatol. fundam. 2010; 13(2):253-264.

42. Lopes TS, Dahl CM, Serpa Júnior OD, Leal EM, Onocko Campos RT, Diaz AR. O processo de restabelecimento na perspectiva de pessoas com diagnóstico de transtornos do espectro esquizofrênico e de psiquiatras na rede pública de atenção psicossocial. Saúde e Sociedade 2012; 21(3):558-571.

43. Good B. Medicine, rationality, and experience. Cambridge: Cambridge University Press; 1994.

44. Dahl C. Experiência, narrativa e intersubjetividade: o processo de restabelecimento (recovery) na perspectiva de pessoas com diagnóstico de esquizofrenia em tratamento nos centros de atenção psicossocial [dissertação]. Campinas: Universidade Estadual de Campinas; 2012.

Artigo apresentado em 01/04/2013

Aprovado em 17/05/2013

Versão final apresentada em 05/06/2013 